\title{
Low Weight Gain in Pregnancy
}

National Cancer Institute

\section{Source}

National Cancer Institute. Low Weight Gain in Pregnancy. NCI Thesaurus. Code C112849.

In a woman with a normal weight pre-pregnancy body mass index (BMI), i.e. 18.5-24.9,

the weight gained during pregnancy does not exceed a total weight gain of $25 \mathrm{lbs}$. In a woman with an underweig ht pre-pregnancy body mass index (BMI), i.e. less than 18.5, the weight gained during pregnancy does not exceed a total weight gain of $28 \mathrm{lbs}$. In a woman with an overweight pre-pregnancy body mass index (BMI), i.e. 25.0-29.9, the weight gained during pregnancy does not exceed a total weight gain of $15 \mathrm{lbs}$. In a woman with an obese pre-pregnancy body mass index (BMI), i.e. greater than 30 , the weight gained during pregnancy does not exceed a total weight gain of $11 \mathrm{lbs}$. These standards are supported for the whole population irrespective of height, race or ethnicity. 